\title{
A Design of Compact Wideband Antenna Based on Hybridization of Minkowski Fractal Curves on Hexagonal Patch and Partial Ground Plane with Truncated Corners
}

\section{Gurpreet Bharti ( $\nabla$ er.gurpreetbharti@gmail.com )}

Yadavindra College of Engineering Department of Electronics and Communication Engineering Jagtar Singh Sivia

Yadavindra College of Engineering Department of Electronics and Communication Engineering

\section{Research Article}

Keywords: wideband antenna, stub, FR4, partial ground plane, Minkowski curve, fractal

Posted Date: March 16th, 2021

DOI: https://doi.org/10.21203/rs.3.rs-261417/v1

License: (c) (1) This work is licensed under a Creative Commons Attribution 4.0 International License. Read Full License

Version of Record: A version of this preprint was published at Wireless Personal Communications on November 30th, 2021. See the published version at https://doi.org/10.1007/s11277-021-09422-y. 


\title{
A Design of Compact Wideband Antenna Based on Hybridization of Minkowski Fractal Curves on Hexagonal Patch and Partial Ground Plane with Truncated Corners
}

\author{
${ }^{1}$ Gurpreet Bharti, ${ }^{2}$ Dr. Jagtar Singh Sivia \\ ${ }^{1}$ Assistant Professor Yadavindra College of Engineering, Punjabi University, GKC Talwandi Sabo, \\ Bathinda, Punjab, India 151302. Email Id: er.gurpreetbharti@gmail.com \\ ${ }^{2}$ Professor Yadavindra College of Engineering, Punjabi University GKC, Talwandi Sabo, Bathinda, \\ Punjab, India 151302. Email Id: jagtarsivian@gmail.com
}

\begin{abstract}
In this manuscript, a compact wideband antenna using a partial ground plane has been designed by the hybridization of Minkowski fractal curves on the hexagonal radiating patch. Further, the corners of this partial ground plane have been truncated and the Minkowski curves superimposed on each truncated corner and finally, the $\mathrm{L}$ - shaped stub has been employed to enhance the performance parameters of the antenna in terms of the number of frequency bands and impedance bandwidth. Different prototypes of an antenna have been compared and found that prototype with $\mathrm{L}$ - shaped stub and ground plane with truncated corners using Minkowski curve (proposed prototype) exhibits better antenna performance parameters. The proposed prototype of the antenna reveals the maximum bandwidth of $10.86 \mathrm{GHz}(140.10 \%)$ with four distinct frequency bands 4.4, 7.1, 10.8, 16.3GHz. Designed antenna has also been fabricated and tested for authentication of simulated results with measured results and found in reasonable agreement with each other. The proposed antenna uses a low-cost FR4 substrate with a compact overall size of $24 \times 30 \times 1.6 \mathrm{~mm} 3$. Due to the wider bandwidth, stable radiation pattern, and gain at the desired frequency points, the proposed antenna can be used for different wireless applications.
\end{abstract}

Keywords: wideband antenna, stub, FR4, partial ground plane, Minkowski curve, fractal

\section{Introduction}

In this current period, the striking changes have been noted in the correspondence development i.e.; guided media is completely replaced by unguided media. These reformist changes are unfathomable without the correct plan structure of the antenna [1]. The most encouraging 
antenna in the new time should be the fractal antenna as it can show multiband/wideband conduct close by downsizing (scaling down) because of its self-likeness and space-filling properties [2, 3]. Fractal antennas are generally utilized for the framework that needs a high information rate and broadband conduct for wideband interchanges. Presently, a day the developing interest in remote frameworks needs smaller measured antennas with more extensive data transmission and multiband qualities with improved reflection coefficient $[4,5]$. Fractals are generally a unique structure that happens normally or can be delivered by utilizing Iterative Recursive Procedure [6]. The properties of the fractal are space-filling, partial measurements, self-likeness, and endless intricacy because they show novel qualities for example, wideband and multiband [7,8]. Space-filling and Self closeness are the main properties of fractal calculations. Space-filling property assists with lessening the size of the antenna i.e.; scaling down of size of the antenna by improving the effective penetrability and permittivity of the substrate,though selflikeness is valuable to accomplish the multiband/wideband attributes [9]. Minkowski, Meander, Koch Hilbert, Sierpinski Gasket/Carpet, and Giuseppe Peano geometries used for the design of fractal antennas. Numerous researchers have attached these fractal geometries to compose the pattern of different antennas for various wireless applications. These invented geometries are named Hybrid antennas.

Siakavara et al. [10] has designed the direct radiating arrays (DRAs) termed as hybrid - fractal. The main advantage described by the author to use proposed technique is to reduce the cost along with size. Azaro et al. [11] has illustrated a hybrid pre-fractal antenna which is being obtained by superimposing the Sierpinski and a Meander structure and it can be useful for GSM and Wi-Fi frequency bands. Chang et al. [12] have demonstrated a traveling-wave hybrid fractal antenna. Authors have reported the enhanced antenna performance parameters by hybridization of various geometries. Soni et al. [13] have investigated the hybrid Minkowskized fractal antenna prototype and found that proposed antenna resonates at six distinct frequency bands. Gashtasbi et al. [14] explained a novel hybrid fractal antenna using Koch and Minkowski geometry which is useful for GSM900MHz application and reported adequate radiation pattern. Rajkumar et al. [15] investigated the MIMO multiband hybrid antenna based on a combination of altered dragon curve and inverted Koch curve. After broadly going through the aforementioned literature, in this manuscript, a hybrid fractal antenna has been designed by superimposing the Minkowski curves on the hexagonal radiating patch and truncated corners of the partial ground plane along with $\mathrm{L}$ - shaped stub. The designed antenna can be used for 
different wireless applications after conscientiously inspecting and analysing the performance parameters of the antenna.

\section{Proposed Antenna Design Stages}

This section emphasizes the various design stages and investigation of the parametric study of the simulated proposed antenna. In this manuscript, the hybrid antenna has been obtained by superimposing the Minkowski curve on a hexagonal radiating patch. The process of designing the Minkowski fractal curve and the procedure of combining it with a hexagonal patch is discussed in detail in the upcoming sub-sections

\subsection{Design process of Minkowski fractal curve}

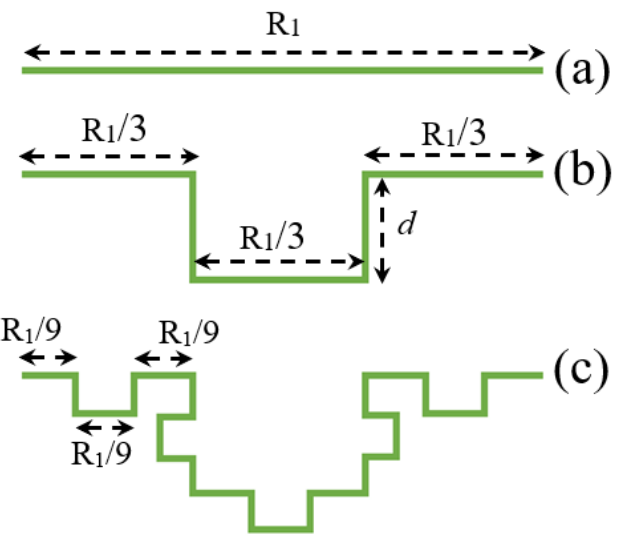

Fig. 1. (a) Initiator geometry, (b) generator structure and (c) proposed Minkowski curve

The structure of the Minkowski fractal curve with $90^{\circ}$ indentation angle $(\theta)$ is designed by using the straight-line called initiator as shown in Fig. 1(a), and the generator structure of the fractal curve is shown in Fig. 1(b). This recursive process has been repeated up to $2^{\text {nd }}$ iteration as delineated in Fig. 1(c), to get the required fractal (Minkowski) shape by using the mathematical tool called IFS (Iterated Function System), and its dimensions are evaluated as [17]:

$$
\text { Indentation Factor }(\rho)=\frac{d}{R_{1} / 3}
$$

Where, $d$ is the depth of indentation and $\mathrm{R}_{1} / 3$ is the fractional part of $\mathrm{R}_{1}$. 
IFS are a convenient mathematical tool used for the construction of fractal geometries by applying affine transformations $(K)$ to a basic geometry $(Z)$. Affine conversion contains translation, scaling and rotation and can be characterized as:

$$
K(x)=Z x+t=\left[\begin{array}{ll}
a & b \\
c & d
\end{array}\right]\left[\begin{array}{l}
x_{1} \\
x_{2}
\end{array}\right]\left[\begin{array}{l}
e \\
f
\end{array}\right]
$$

Where matrix $Z$ (initial geometry) is given as:

$$
Z=\left[\begin{array}{ll}
\left(\frac{1}{s}\right) \cos \theta & -\left(\frac{1}{s}\right) \sin \theta \\
\left(\frac{1}{s}\right) \sin \theta & \left(\frac{1}{s}\right) \cos \theta
\end{array}\right]
$$

Here 'a to d' the parameters are for the rotation and scaling, 'e and f' are for the translation and shifting, ' $\mathrm{s}$ ' is scaling factor, ' $\theta$ ' is the rotation angle, ' $\mathrm{t}$ ' represents the transformation factor and ' $\mathrm{X} 1, \mathrm{X} 2$ ' signifies the coordinate points of $\mathrm{x}$.

The equation (4) used to obtain fractal geometry with the application of the set of linear transformation on ' $Z$ ' and using Hutchinson operator $(K)$

$$
K(Z)=\bigcup_{n=1}^{N} K_{N}(Z)
$$

The transformation of individual segment can generate the desired geometry of fractal curve as illustrated in Fig. 1(c). Thus, the proposed curve can be obtained by using above mentioned operator $(K)$ and is represented by:

$$
\begin{aligned}
& K_{1}\left[\begin{array}{l}
x_{1} \\
x_{2}
\end{array}\right]=\left[\begin{array}{cc}
0.333 & 0 \\
0 & 0.333
\end{array}\right]\left[\begin{array}{l}
x_{1} \\
x_{2}
\end{array}\right]+\left[\begin{array}{l}
0 \\
0
\end{array}\right] \\
& K_{2}\left[\begin{array}{l}
x_{1} \\
x_{2}
\end{array}\right]=\left[\begin{array}{cc}
0 & 0.200 \\
-0.200 & 0
\end{array}\right]\left[\begin{array}{l}
x_{1} \\
x_{2}
\end{array}\right]+\left[\begin{array}{c}
0.333 \\
0
\end{array}\right] \\
& K_{3}\left[\begin{array}{l}
x_{1} \\
x_{2}
\end{array}\right]=\left[\begin{array}{cc}
0.333 & 0 \\
0 & 0.333
\end{array}\right]\left[\begin{array}{l}
x_{1} \\
x_{2}
\end{array}\right]+\left[\begin{array}{c}
0.333 \\
-0.200
\end{array}\right] \\
& K_{4}\left[\begin{array}{l}
x_{1} \\
x_{2}
\end{array}\right]=\left[\begin{array}{cc}
0 & -0.200 \\
0.200 & 0
\end{array}\right]\left[\begin{array}{l}
x_{1} \\
x_{2}
\end{array}\right]+\left[\begin{array}{c}
0.666 \\
-0.200
\end{array}\right] \\
& K_{5}\left[\begin{array}{l}
x_{1} \\
x_{2}
\end{array}\right]=\left[\begin{array}{cc}
0.333 & 0 \\
0 & 0.333
\end{array}\right]\left[\begin{array}{l}
x_{1} \\
x_{2}
\end{array}\right]+\left[\begin{array}{c}
0.666 \\
0
\end{array}\right]
\end{aligned}
$$


Where $K_{1}, K_{2}, K_{3}, K_{4}$ and $K_{5}$ represents a set of linear transformation and the originator curve of Minkowski fractal is then attained using $\mathrm{K}(\mathrm{Z})=K_{1}(Z) \mathrm{U} K_{2}(Z) \mathrm{U} K_{3}(Z) \mathrm{U} K_{4}(Z) \mathrm{U} K_{5}(Z)$. This procedure is repeated for obtaining the further iterations of the desired Minkowski curve. The self-similarity index (D), can be obtained using the following equation:

$$
D=\frac{\log (N)}{\log (r)}
$$

By using the above-mentioned process, the different and similar types of fractal geometries and iterations can be generated. In this paper, two iterations of Minkowski curve have been designed. The total length of the designed curve has been evaluated by taking the value of ' $n=2$ ' using the following equation:

$$
l=h\left(\frac{N}{r}\right)^{n}
$$

Here ' $h$ ' represents the height of curve, ' $r$ ' represents the number of segments divided on iteration, 'N' designates the number of segments, 'n' designates the number of iterations.

\subsection{Design of proposed Hybrid antenna}

The proposed hybrid antenna is a combination of two different geometries. The fractal curve designed in the previous sub-section has been superimposed on each side of the hexagonal patch. After applying the fractal curves on the radiating patch, it has been combined with $50 \Omega$ transmission line feed and fractional ground plane (FGP) as shown in Fig. 2(a). Proposed structure of antenna has been printed on a low cost FR4 glass epoxy substrate with thickness $\mathrm{h}=$ $1.6 \mathrm{~mm}$, loss tangent $\delta_{e}=0.02$, dielectric constant $\varepsilon_{r}=4.4$, mass density of $19,000 \mathrm{~kg} / \mathrm{m}^{3}$ and the resonant frequency $f_{r}=5.65 \mathrm{GHz}$. By considering the aforementioned parameters, the radius of the hexagonal patch has been calculated as $\mathrm{R}=7 \mathrm{~mm}$ using the following equation [18].

$$
R=\frac{F}{\left\{1+\frac{2 h}{\pi F \varepsilon_{r}}\left[\ln \left(\frac{\pi F}{2 h}\right)+1.7726\right]\right\}^{\frac{1}{2}}}
$$

Where, $F=\frac{8.791 \times 10^{9}}{f_{r} \sqrt{\varepsilon_{r}}}$ 
In compact-sized antenna radiators, the proper impedance matching is a relatively cumbersome method. Hence, to improve this problem the parametric dimensions of FGP have been changed further to attain better impedance matching characteristics and wider bandwidth as illustrated in Fig. 2(b). Further, the corners of the rectangular fractional ground plane have been truncated with side length T2 and T3 for both the lower and upper edges as shown in Fig. 2(c); the side length of truncated corners are the same as the side length of the hexagonal radiating patch. The designed fractal curve is overlaid on the truncated corners of the fractional ground plane as shown in Fig. 2(d), to analyze the performance of a proposed antenna. Finally, the inverted Lshaped stub is employed in the geometry of the ground plane as depicted in Fig. 2(e) to obtain the wider bandwidth and improve the reflection coefficient in the desired frequency range. The optimized dimensions of the proposed hybrid antenna are illustrated in Table 1.

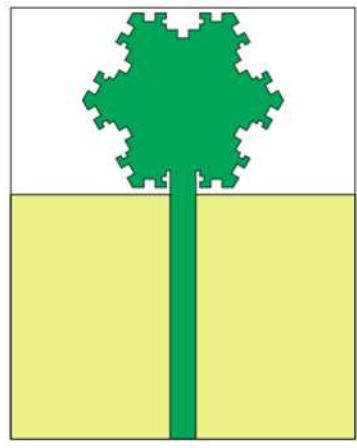

(a) Prototype - 1

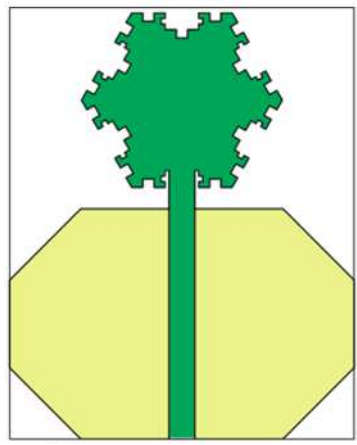

(c) Prototype -3

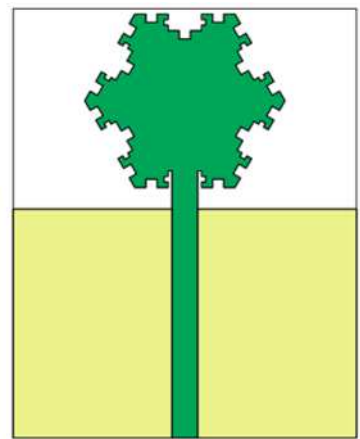

(b) Prototype -2

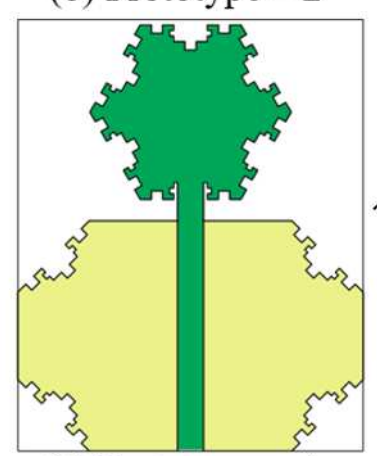

(d) Prototype -4

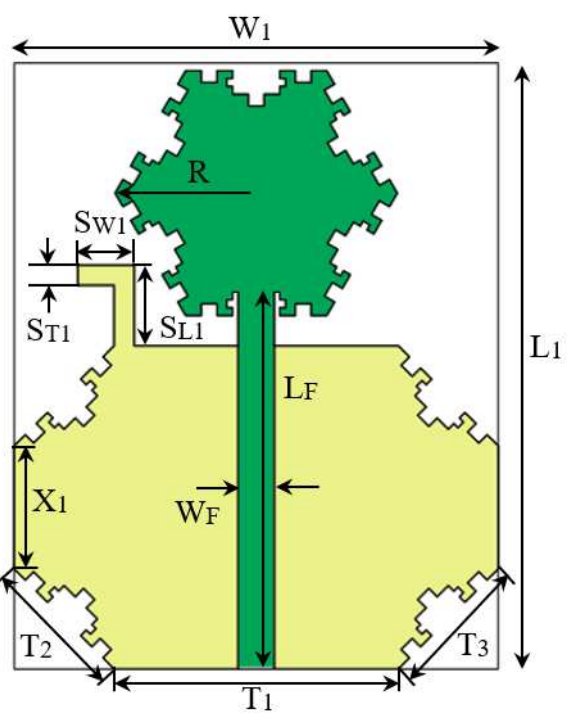

(e) Proposed Prototype

Fig. 2 . Design evolution of the proposed hybrid antenna (a) Iteration - 1, (b) Iteration - 2, (c) Iteration -3 , (d) Iteration -4 and (e) Iteration -5 (proposed prototype) 
Table 1: Optimal value of different dimensions of the proposed antenna

\begin{tabular}{llllll}
\hline Parameters & $\begin{array}{l}\text { Optimized } \\
\text { Value } \\
(\mathrm{mm})\end{array}$ & Parameters & $\begin{array}{l}\text { Optimized } \\
\text { value } \\
(\mathrm{mm})\end{array}$ & Parameters & $\begin{array}{l}\text { Optimized } \\
\text { Value } \\
(\mathrm{mm})\end{array}$ \\
\hline $\mathrm{R}$ & 7.0 & $\mathrm{~W}_{1}$ & 24.0 & $\mathrm{X}_{1}$ & 6.1 \\
$\mathrm{LF}_{\mathrm{W}}$ & 18.665 & $\mathrm{~T}_{1}$ & 14.1 & $\mathrm{~S}_{\mathrm{W} 1}$ & 2.8 \\
$\mathrm{~W}_{\mathrm{F}}$ & 1.8 & $\mathrm{~T}_{2}$ & 7.0 & $\mathrm{~S}_{\mathrm{T} 1}$ & 1.0 \\
$\mathrm{~L}_{1}$ & 30.0 & $\mathrm{~T}_{3}$ & 7.0 & $\mathrm{~S}_{\mathrm{L} 1}$ & 4.0 \\
\hline
\end{tabular}

The effects of designed prototypes from the initial stage (prototype -1 ) to the final stage (proposed prototype) in terms of $S_{11}$ and impedance bandwidth have been depicted in Fig. 3. It is observed from Fig. 3, that the prototype -1 and 2 of the designed antenna exhibits three frequency bands with a maximum bandwidth of 6.67 and $8.0 \mathrm{GHz}$ respectively. While the other two prototypes exhibit only two frequency bands and reveal the maximum bandwidth of 8.32 and $9.50 \mathrm{GHz}$ respectively. From the above discussion, it is very much clear that by modifying the geometry of the proposed antenna from the prototype -1 to prototype -4 the impedance bandwidth has been increased. Though the bandwidth has been improved the reflection coefficient is degraded and also the number of frequency bands gets reduced. To overcome this problem the final geometry (proposed prototype) has been designed by introducing the inverted $\mathrm{L}$ - shaped stub in the geometry of prototype -4 , to obtain more frequency bands with improved bandwidth and reflection coefficient. It has been revealed that a proposed prototype of the designed antenna exhibits four distinct resonance frequency points with enhanced reflection coefficient and a maximum bandwidth of $10.86 \mathrm{GHz}$. The mathematical results of all the designed prototype of the proposed antenna are tabulated in Table 2 for the better understanding. 


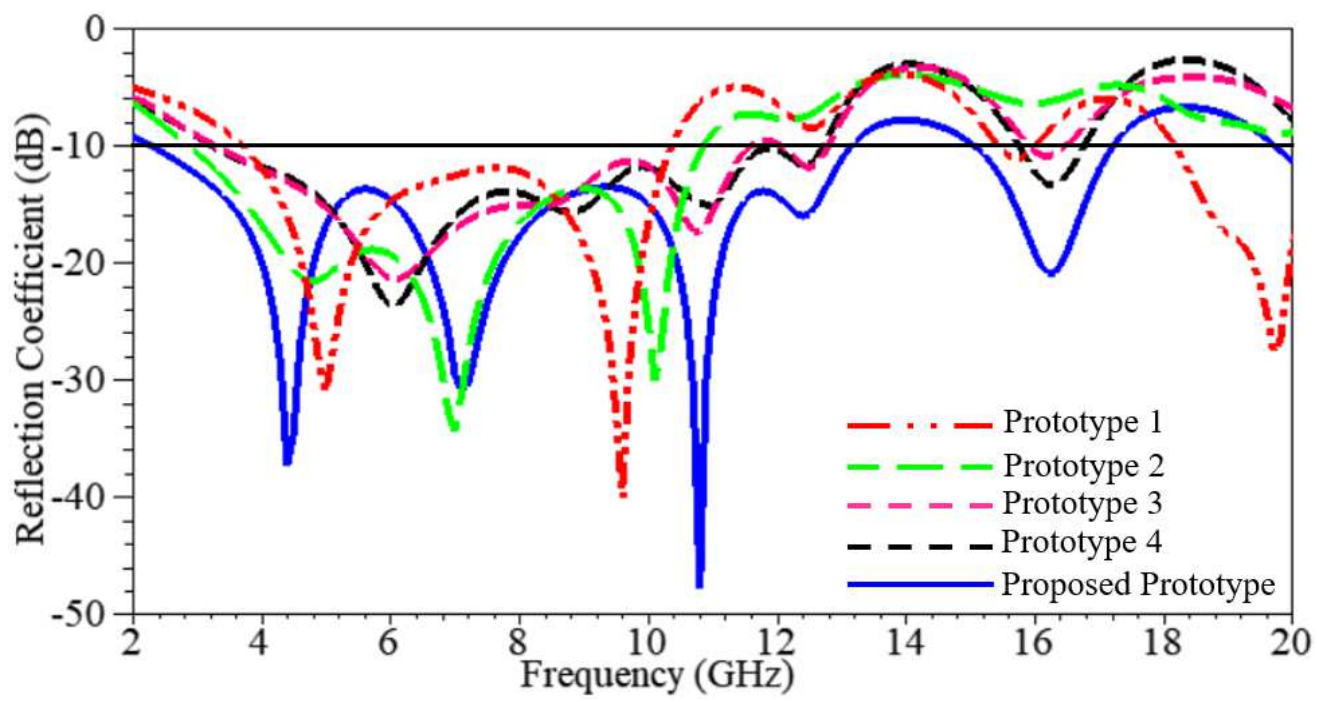

Fig. 3. S11 plot for the different prototypes of the proposed hybrid antenna

Table 2: Comparison of results for different prototypes of proposed hybrid antenna

\begin{tabular}{ccccc}
\hline $\begin{array}{c}\text { Antenna } \\
\text { Design }\end{array}$ & $\begin{array}{c}\text { Resonant frequency } \\
\text { points (GHz) }\end{array}$ & $\begin{array}{c}\text { Maximum } \\
\text { Bandwidth } \\
(\mathrm{GHz})\end{array}$ & $\begin{array}{c}\text { Bandwidth } \\
\text { Ratio }\end{array}$ & $\begin{array}{c}\text { Bandwidth } \\
(\%)\end{array}$ \\
\hline Prototype -1 & $5.0 / 9.6 / 19.7$ & 6.67 & $2.80: 1$ & 94.81 \\
\hline Prototype -2 & $4.7 / 7.0 / 10.1$ & 8.0 & $3.78: 1$ & 116.44 \\
\hline Prototype -3 & $6.1 / 10.8$ & 8.32 & $3.53: 1$ & 111.82 \\
\hline Prototype -4 & $6.1 / 16.3$ & 9.50 & $3.95: 1$ & 119.19 \\
\hline $\begin{array}{c}\text { Proposed } \\
\text { Prototype }\end{array}$ & $4.4 / 7.1 / 10.8 / 16.3$ & 10.86 & $5.72: 1$ & 140.10 \\
\hline
\end{tabular}

The performance parameter like impedance bandwidth of the proposed hybrid antenna has also been analysed by optimizing its different parameters such as 'WF' feed line width and 'SW1' width of stub arm. The 'WF' and 'SW1' parameters have been varied from $1.0 \mathrm{~mm}$ to $1.8 \mathrm{~mm}$ with an increased step size of $0.2 \mathrm{~mm}$ as delineated in Fig. 4 and Fig. 5 respectively. It can be analysed from both the figures that the proposed hybrid antenna exhibits the wider bandwidth and improved reflection coefficient only at $\mathrm{WF}=1.8 \mathrm{~mm}$ and $\mathrm{SW} 1=1.8 \mathrm{~mm}$. Thus, the optimal values of the abovementioned parameters have been fixed to $1.8 \mathrm{~mm}$ for better performance in terms of bandwidth and reflection coefficient. 


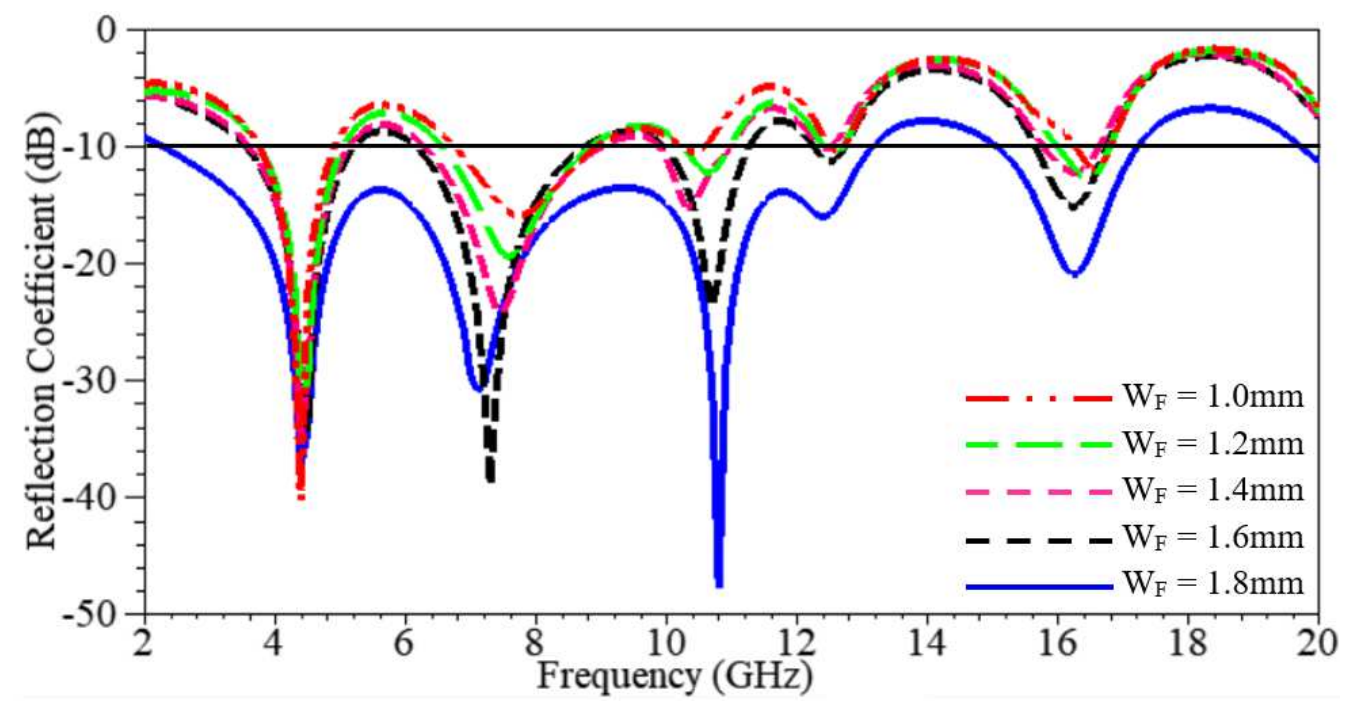

Fig. 4. S11 plot of proposed hybrid antenna at different values of 'WF' parameter

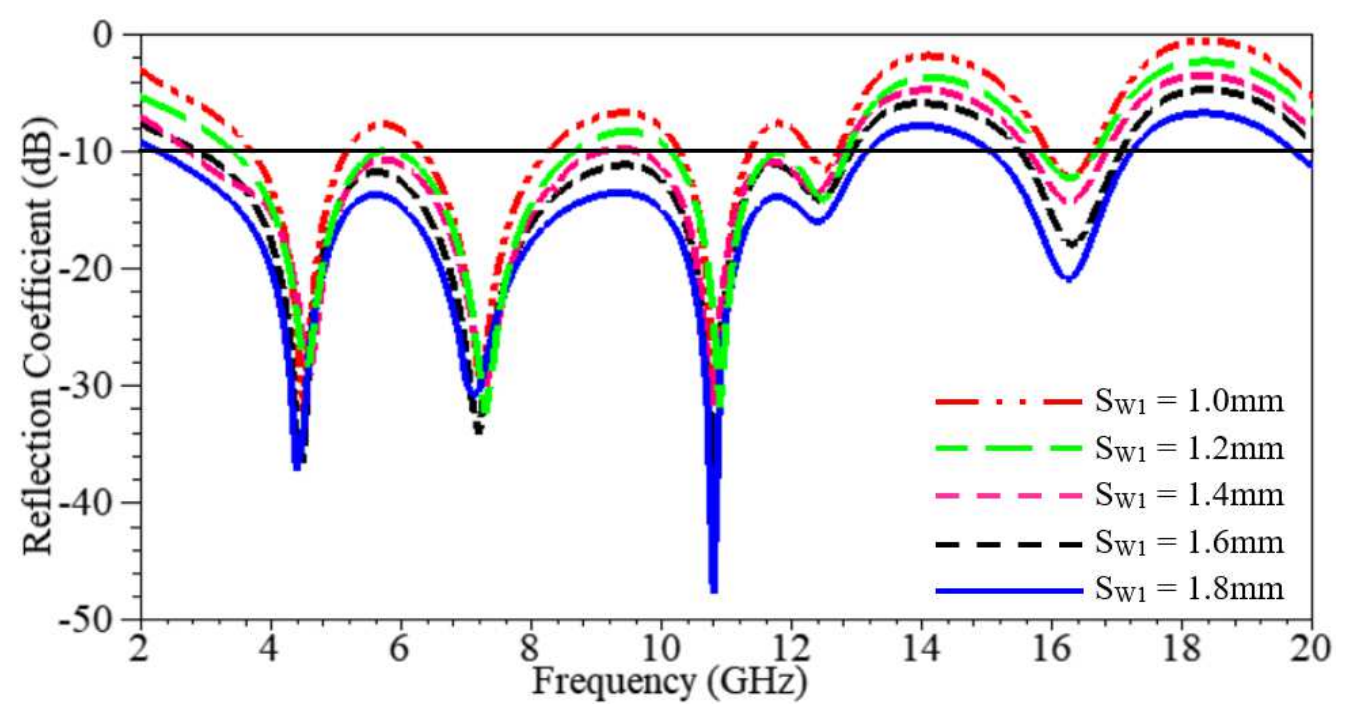

Fig. 5. S 11 plot of proposed hybrid antenna at different values of 'Sw1' parameter

The current distribution plot for both the surfaces (radiating patch and ground plane) of the proposed hybrid antenna at distinct frequency points are illustrated in Fig. 6. From this figure it can be observed that a strong current is concentrated on inverted L- shaped stub and transmission line along the ground plane at the resonance points of $4.4,7.1$, and $10.8 \mathrm{GHz}$. The strong current generation on the stub helps in attaining the broad bandwidth and improved reflection coefficient at these frequency bands. Similarly, the reflection coefficient is improved at $16.3 \mathrm{GHz}$ due to the concentration of strong current at the feed line and lower edge of the hexagonal patch as shown in Fig. 6(d). So, from the aforementioned discussion, it is clear that the effects of the truncated ground plane with inverted L-shaped stub play a very important role 
in the various performance parameters like impedance bandwidth and $\mathrm{S}_{11}$ of the proposed hybrid antenna.

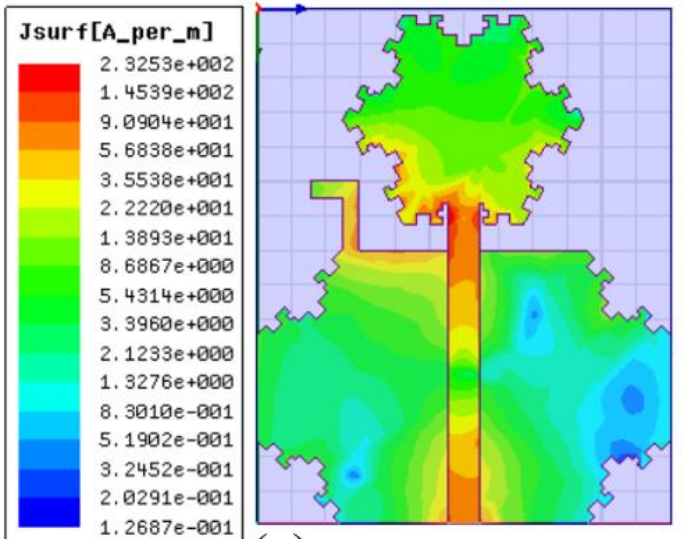

(a)

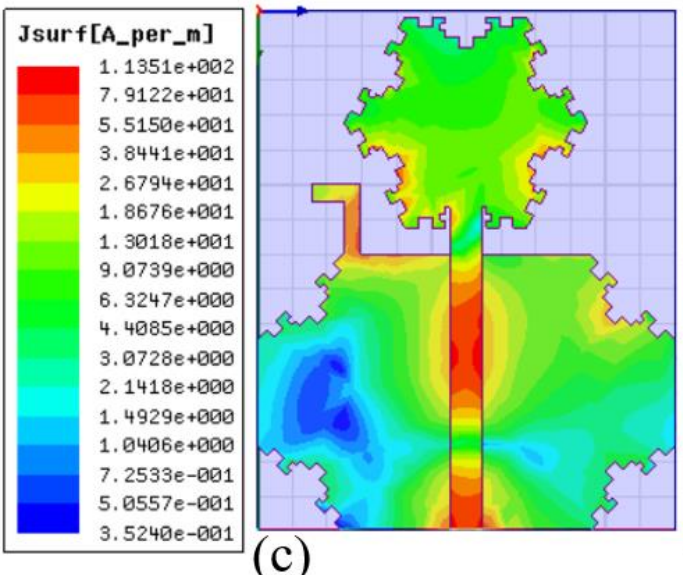

(c)

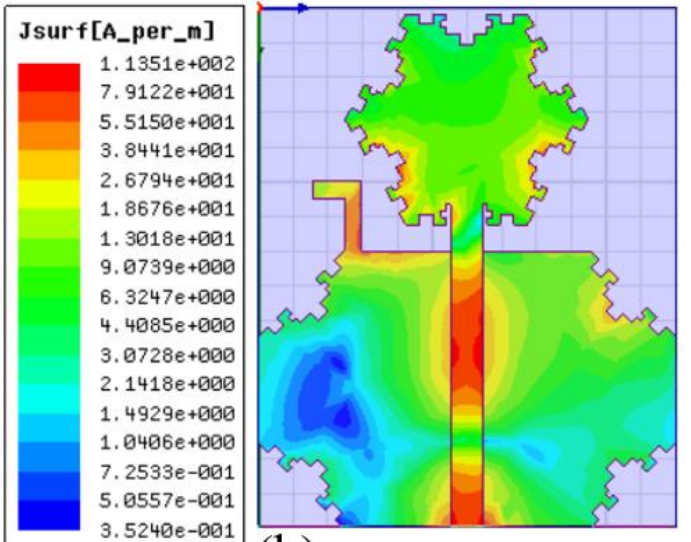

(b)

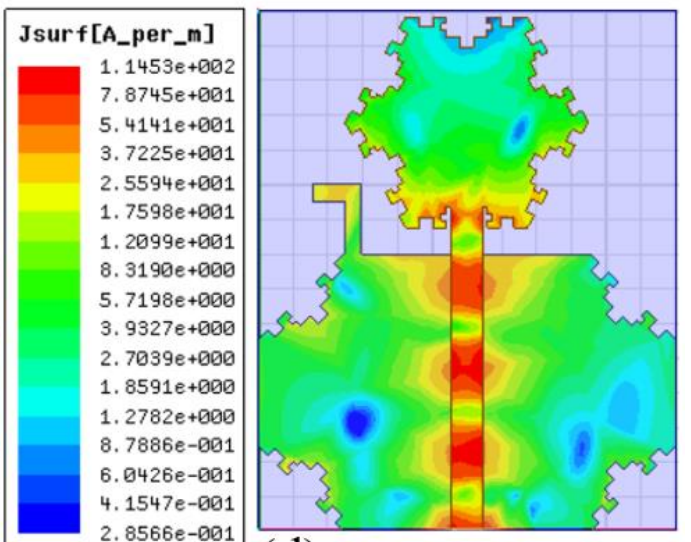

(d)

Fig. 6. Simulated surface current distribution plot of proposed hybrid antenna at (a) $4.4 \mathrm{GHz}$, (b) $7.1 \mathrm{GHz},(\mathrm{c}) 10.8 \mathrm{GHz}$ and (d) $16.3 \mathrm{GHz}$ frequency points

\section{Fabricated Prototype and Results}

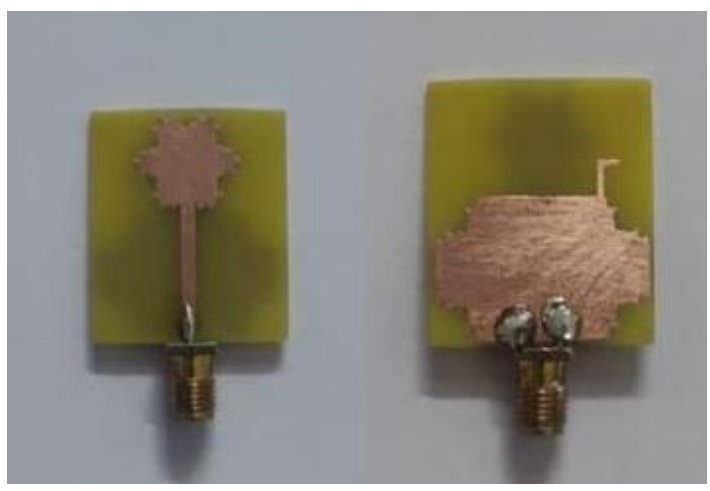

Fig. 7. Front and rear view of fabricated prototype of proposed hybrid antenna 


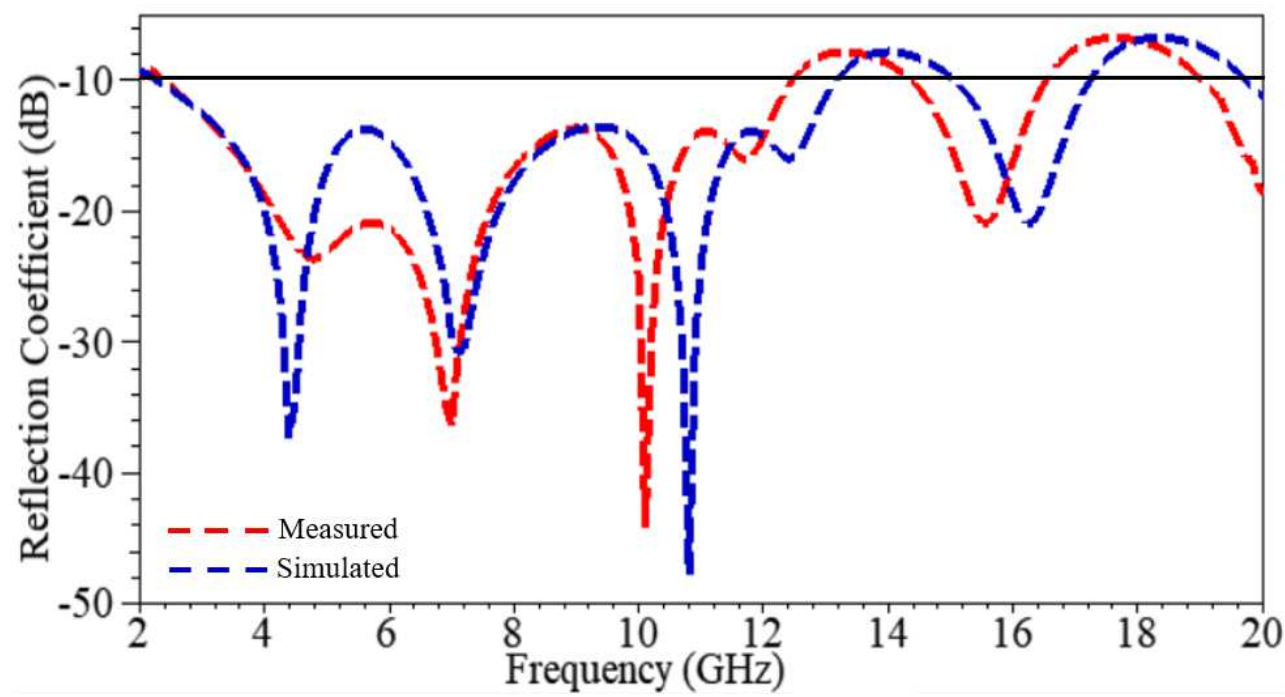

Fig. 8. Simulated and measured reflection coefficient plot of proposed hybrid antenna

This section reveals the comparison of simulated and measured results of the proposed hybrid antenna and the fabricated prototype of the designed antenna (front and rear view) as illustrated in Fig. 7. The fabricated prototype of the antenna has been tested by using a vector network analyser (VNA) with a frequency range from $1 \mathrm{MHz}$ to $20 \mathrm{GHz}$ and the experimental reflection coefficient is compared with simulated as shown in Fig. 8. It clears results that they have good agreement with each other, due to the small variations in both the curves (simulated and measured). The simulated antenna exhibits the maximum bandwidth of $10.86 \mathrm{GHz}$ with resonance points of $4.4,7.1,10.8$, and $16.3 \mathrm{GHz}$. Whereas, the measured antenna shows the maximum impedance bandwidth of $10.05 \mathrm{GHz}$ with frequency bands of 4.8, 7.0, 10.1, and 15.5GHz. These variations are due to the environmental conditions, soldering bumps, connector losses physical properties of a fabricated prototype, etc. 

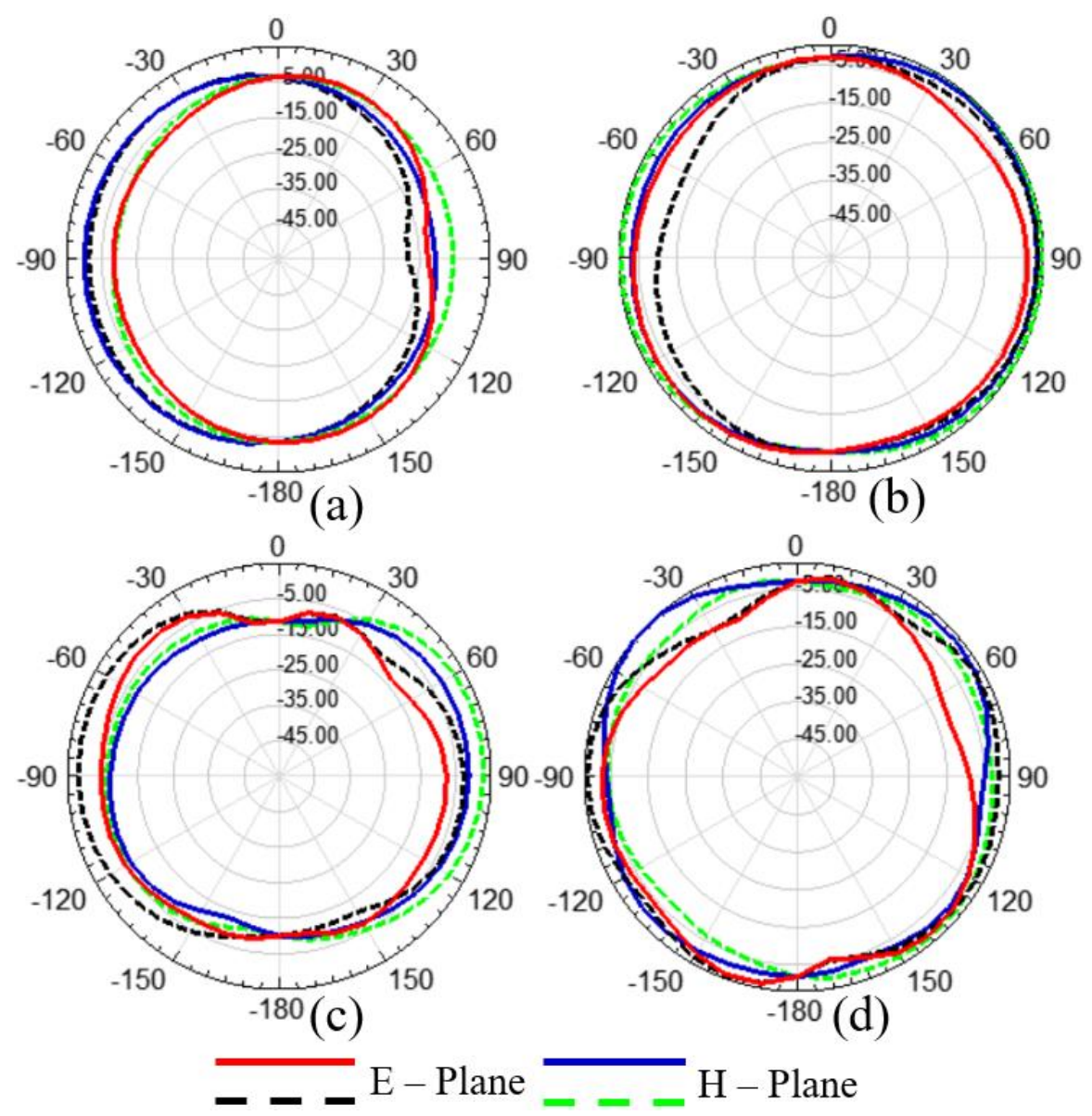

Fig. 9. Radiation pattern of proposed hybrid antenna at (a) $4.4 \mathrm{GHz}$, (b) $7.1 \mathrm{GHz}$, (c) $10.8 \mathrm{GHz}$ and (d) $16.3 \mathrm{GHz}$ frequency points (solid line: simulated and dashed line: measured)

The radiation properties of a proposed hybrid antenna have been analyzed with the help of its radiation patterns in $\mathrm{E}$ and $\mathrm{H}$ - planes. So, the radiation patterns of the proposed antenna have been measured at distinct frequency points and compared with the simulated patterns as illustrated in Fig. 9. It shows that antenna represents the stable omnidirectional radiation pattern in both the planes ( $\mathrm{E}$ and $\mathrm{H}$ - plane) at all the frequency bands of operation. Due to the omnidirectional properties of a proposed hybrid antenna, which indicates that it can be used for different wireless applications in the operational frequency range. The gain plot of a proposed antenna (simulated and measured) is depicted in Fig. 10, it is clear that the antenna exhibits the positive value of gain in the desired frequency range from 2.30 to $13.16 \mathrm{GHz}$ for simulated antenna and 2.40 to $12.45 \mathrm{GHz}$ for measured antenna. The proposed antenna exhibits the maximum gain of $4.54 \mathrm{~dB}$ at $2.3 \mathrm{GHz}$ and a stable positive gain at all the other frequency points. From, the above discussion it can be said that due to the stable radiation pattern and gain at all 
the frequency points in the desired frequency range the proposed antenna can be used for different wireless standards such as LTE 2300/LTE $2500(2.3-2.4 \mathrm{GHz} / 2.5-2.69 \mathrm{GHz})$, Bluetooth (2.4GHz), WLAN $(2.4-2.48,5.15-5.35 \mathrm{GHz})$, WiMAX (3.3 - 3.7GHz), ISM $(5.725$ $-5.875 \mathrm{GHz})$, ITU band $(7.8-8.4 \mathrm{GHz})$, television broadcasting $(7.91-8.62 \mathrm{GHz}$, point-to-point wireless applications $(5.92-8.5 \mathrm{GHz})$ and aeronautical radio navigations $(15.43-17.3 \mathrm{GHz})$.

In addition to the aforesaid discussion, the proposed hybrid antenna has been compared with the existing hybrid fractal antennas in terms of performance parameters and size as tabulated in Table 3. It is found that the designed antenna is compact and exhibits enhanced bandwidth as compared to the antennas proposed in the state of art literature.

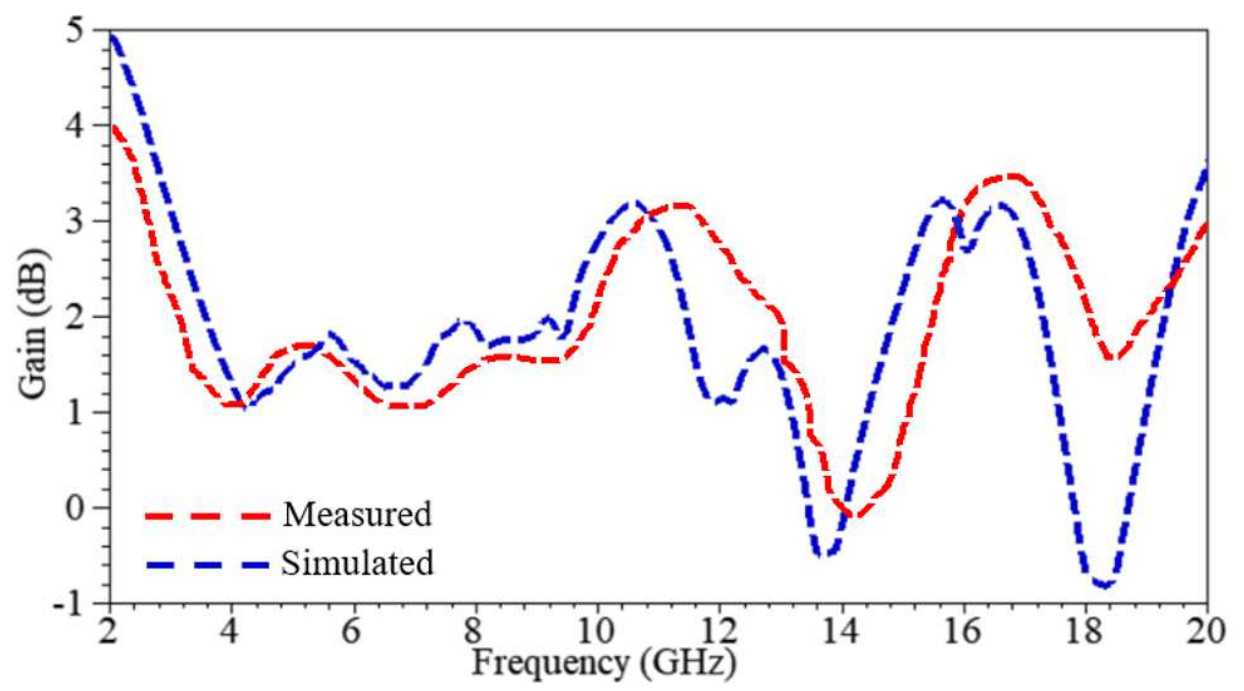

Fig. 10. Simulated and measured peak realized gain of proposed hybrid antenna

Table 3: Assessment of proposed hybrid antenna with existing antennas of same category

\begin{tabular}{cccccc}
\hline Reference & $\begin{array}{c}\text { Dimensions } \\
\text { of antenna } \\
\left(\mathrm{mm}^{2}\right)\end{array}$ & $\begin{array}{c}\text { No. of } \\
\text { freq. bands }\end{array}$ & $\begin{array}{c}\text { Frequencies of Resonance } \\
(\mathrm{GHz})\end{array}$ & $\begin{array}{c}\text { Maximum } \\
\mathrm{BW} \\
(\mathrm{GHz})\end{array}$ & $\begin{array}{c}\text { Maximum } \\
\text { gain } \\
(\mathrm{dBi})\end{array}$ \\
\hline$[19]$ & $25 \times 66$ & 2 & $1.9 / 3.15$ & 1.9 & 4.78 \\
{$[20]$} & $48 \times 36$ & 5 & $1.98 / 5.94 / 10.61 / 12.73 / 14.85$ & 2.83 & 9.0 \\
{$[21]$} & $38 \times 26$ & 5 & $6.30 / 7.30 / 7.40 / 8.30 / 8.60$ & $\mathrm{NA}$ & 8.5 \\
{$[22]$} & $41.5 \times 37$ & 6 & $1.7 / 2.4 / 3.03 / 4.25 / 7.26 / 9.26$ & 2.87 & 20.1 \\
{$[23]$} & $55 \times 60$ & 6 & $1.0 / 1.9 / 2.4 / 5.2 / 5.5 / 8.1$ & 0.99 & 16.65 \\
{$[24]$} & $100 \times 50$ & 4 & $1.75 / 3.0 / 4.5 / 6.0$ & 3.57 & 6.78 \\
{$[25]$} & $30 \times 30$ & 4 & $2.0 / 4.8 / 6.0 / 9.2$ & 7.69 & 4.40 \\
Proposed & $24 \times 30$ & 4 & $4.4 / 7.1 / 10.8 / 16.3$ & 10.86 & 4.54 \\
\hline
\end{tabular}




\section{Conclusion}

The proposed compact wideband antenna using partial ground plane has been designed by hybridization of Minkowski fractal curves on the hexagonal radiating patch has been presented in this manuscript. Different structures of an antenna are compared and found that structure with $\mathrm{L}$ - shaped stub and ground plane with truncated corners using Minkowski curve exhibits better antenna performance in terms of impedance bandwidth and the number of resonant frequency bands. The proposed structure of a hybrid antenna exhibits four distinct frequency bands 4.4, 7.1, $10.8,16.3 \mathrm{GHz}$ with the maximum bandwidth of $10.86 \mathrm{GHz}(140.10 \%)$. The proposed antenna is fabricated and the measured results are compared with simulated and found in reasonable agreement with each other. The antenna exhibits a stable radiation pattern at distinct frequency bands and shows the maximum gain of $4.54 \mathrm{~dB}$ at $2.3 \mathrm{GHz}$. Due to the stable radiation pattern and wider bandwidth and positive gain at the anticipated frequency range, the proposed antenna can be used for different wireless applications such as Bluetooth, WLAN, WiMAX, ISM, television broadcasting, and aeronautical radio navigations.

\section{References}

[1] Sharma N, Sharma V. A journey of antenna from dipole to fractal: A review. Int J Engg Techno 2017; 6:317-51.

[2] Sharma N, Bhatia S-S. Performance enhancement of nested hexagonal ring -shaped compact multiband integrated wideband fractal antennas for wireless applications. Int J RF Microw Comput Aided Engg 2019; 30(3):e22079.

[3] Bhatia S-S, Sivia J-S. On the design of fractal antenna array for multiband applications. J Inst Engg India Ser B 2019; 100:471-476.

[4] Sivia J-S, Bhatia S-S. Design of fractal based microstrip rectangular patch antenna for multiband applications 2015. 10.1109/IADCC.2015.7154799

[5] Bhatia S-S, Sivia J-S. Analysis and design of circular fractal antenna array for multiband applications. Int J Inf Technol 2018. https://doi.org/10.1007/s41870-018-0186-0

[6] Vardadhan C, Pakkathillam J-K, Kanagasabai M, Sivasamy R, Natarajan R, Palaniswamy SK. Triband antenna structures for RFID systems deploying fractal geometry. IEEE Ant and Wirel Propag Lett 2013; 12:437-440.

[7] Singh S, Singh A. Design and optimization of a modified Sierpinski fractal antenna for broadband applications. Appl Soft Comput 2014; 38:843-50. 
[8] Tripathi S, Mohan A, Yadav S. Hexagonal fractal ultra-wideband antenna using Koch geometry with bandwidth enhancement. IET Microw, Ant and Propag 2014; 8(18):1445-50.

[9] Susila M, Rao T-R, Gupta A. A novel fractal antenna design for UWB wireless communications. IEEE Int Microw and RF Conf (IMaRC) 2014; 118-120.

[10] Siakavara K. Hybrid fractal direct radiating antenna arrays with small number of elements for satellite communications. IEEE Trans on Ant and Propag 2010; 58(6):2102-06.

[11] Azaro R, Debiasi L, Zeni E, Benedetti M, Rocca P, Massa A. A hybrid prefractal three-band antenna for multistandard mobile wireless applications. IEEE Ant and Wireless Propag Lett 2009; 8:905-08.

[12] Chang J, Lee S. Hybrid fractal cross antenna. Microw and Optic Technol Lett 2000; 25(6):429-35.

[13] Soni B-K, Singhai R. Design and analysis of Minkowskized hybrid fractal like antenna for multiband operation. Prog In Electromag Res Lett 2018; 80:117-26.

[14] Gashtasbi A, Kaboli O, Monajati A. A novel hybrid fractal loop antenna for GSM900. Int J of Sci \& Eng Res 2017; 8(10):1323-25.

[15]Rajkumar S, Srinivasan N, Natesan A, Selvan K-T. A penta-band hybrid fractal MIMO antenna for ISM applications. Int J RF Microw Comput Aided Eng 2017; 28(2); e21185.

[16] Sharma N, Sharma V, Bhatia S-S. A novel hybrid fractal antenna for wireless applications. Prog In Electromag Res M 2018; 73:25-35.

[17] Bhatia S-S, Sivia J-S, Sharma N. An optimal design of fractal antenna with modified ground plane structure for wideband applications. Wireless Pers Commun 2018; 103:1977-91.

[18] Choukiker Y-K, Behra S-K. Design of wideband fractal antenna with combination of fractal geometries. IEEE Int. Conf. on Info. Commun. Sig. Proces., 2011.

[19]Jindal S, Sivia J-S, Bindra H-S. Hybrid fractal antenna using Meander and Minkowski curves for wireless applications. Wirel Person Commun 2019; 109:1471-90.

[20] Brar A-S, Sivia J-S, Bharti G. A compact hybrid Minkowski fractal antenna for C and Xband applications. Int J of Comp Sci and Info Secu 2016; 14(12):349-52.

[21]Bangi I, Sivia J-S. Moore, Minkowski and Koch curves-based hybrid fractal antenna for multiband applications. Wirel Person Commun 2019; 108:2435-48.

[22] Kaur K, Sivia J-S. A compact hybrid multiband antenna for wireless applications. Wirel Person Commun 2017; 97(4):5917-27. 
[23] Choukiker Y-K, Sharma S-K, Behra S-K. Hybrid fractal shape planar monopole antenna covering multiband wireless communications with MIMO implementation for handheld mobile devices. IEEE Trans Ant Propag 2014; 62(3):1483-88.

[24] Sharma N, Bhatia S-S. Double split labyrinth resonator based CPW fed hybrid fractal antennas for PCS/UMTS/WLAN/Wi-MAX applications. J of Electromag Waves and App $2019 ; 33(18): 2476-98$. 
Figures
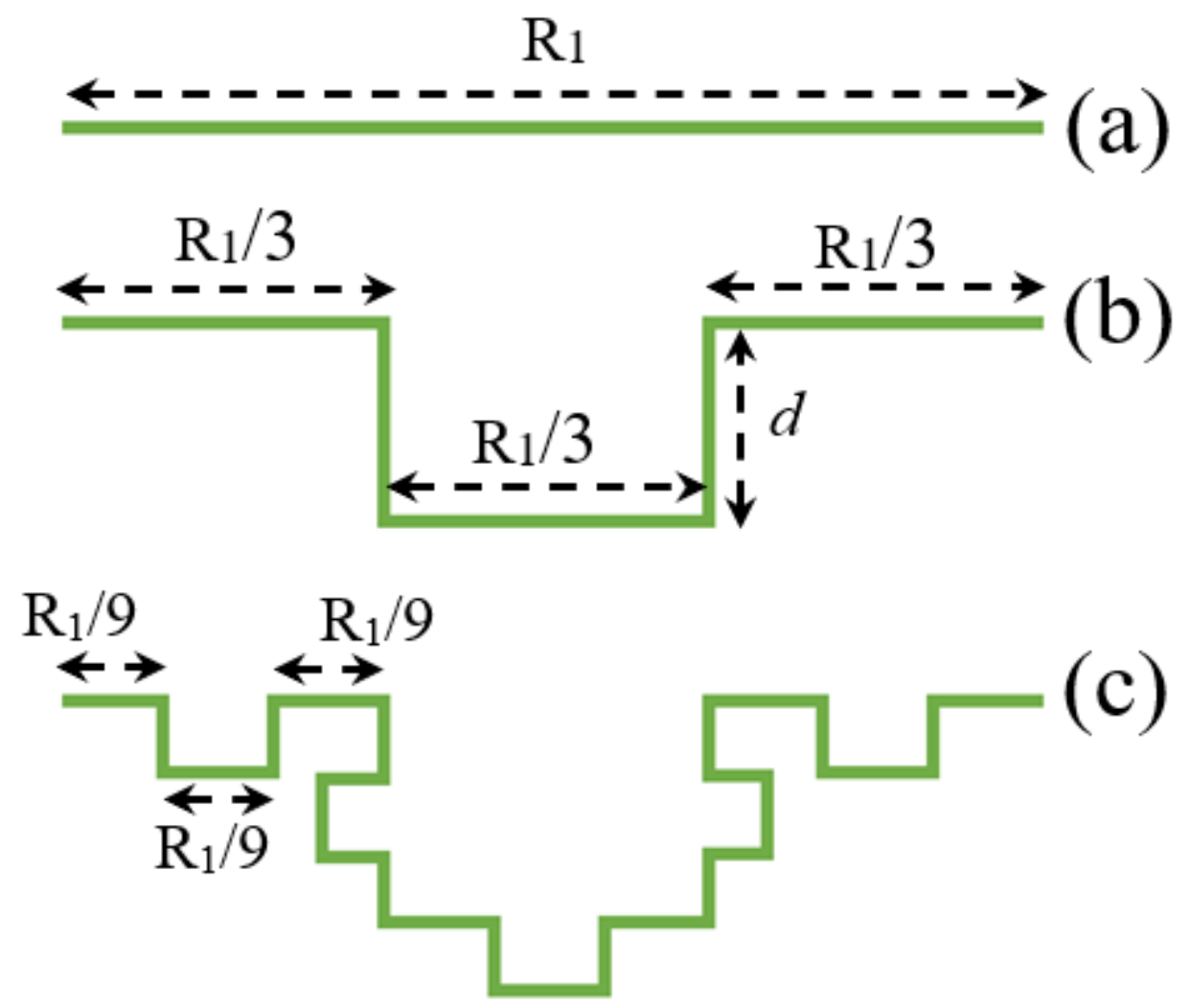

Figure 1

(a) Initiator geometry, (b) generator structure and (c) proposed Minkowski curve 


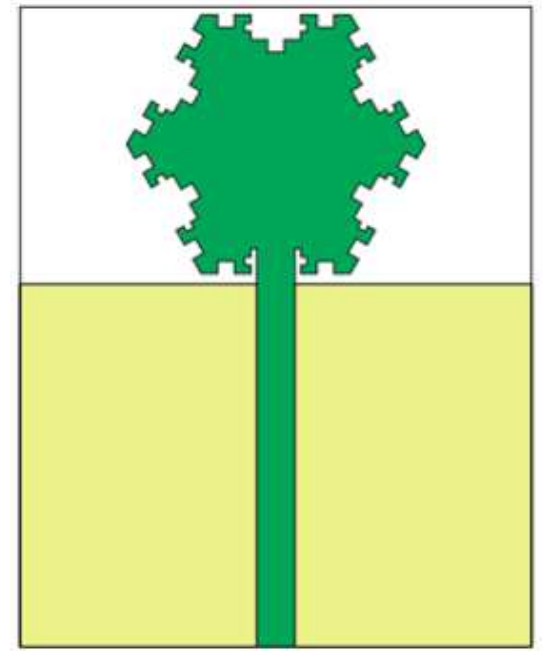

(a) Prototype - 1

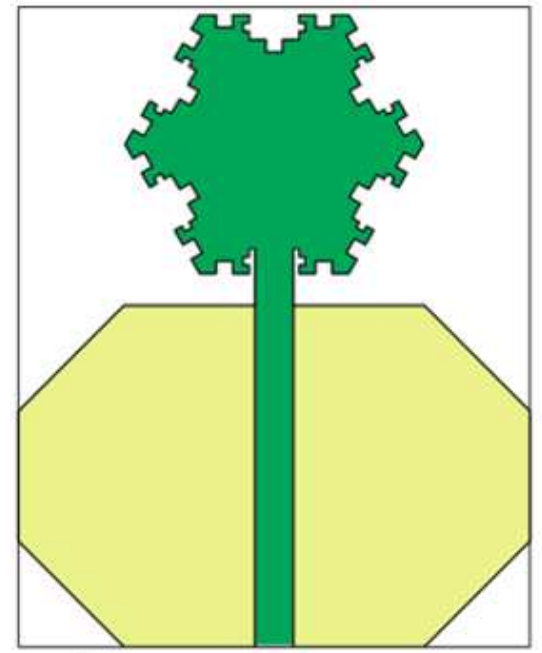

(c) Prototype - 3

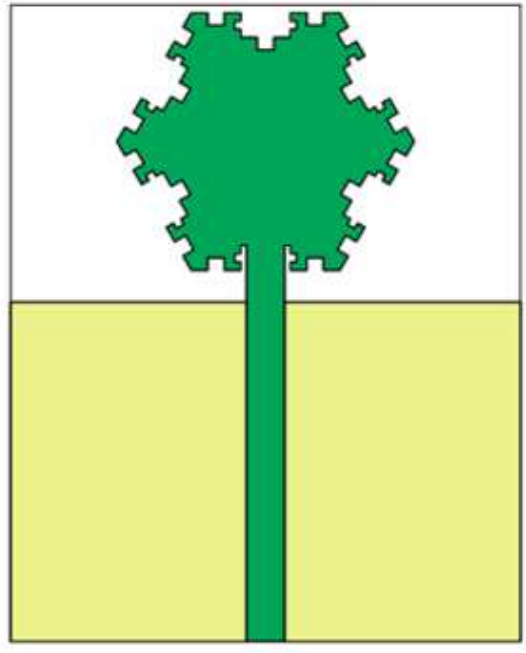

(b) Prototype - 2

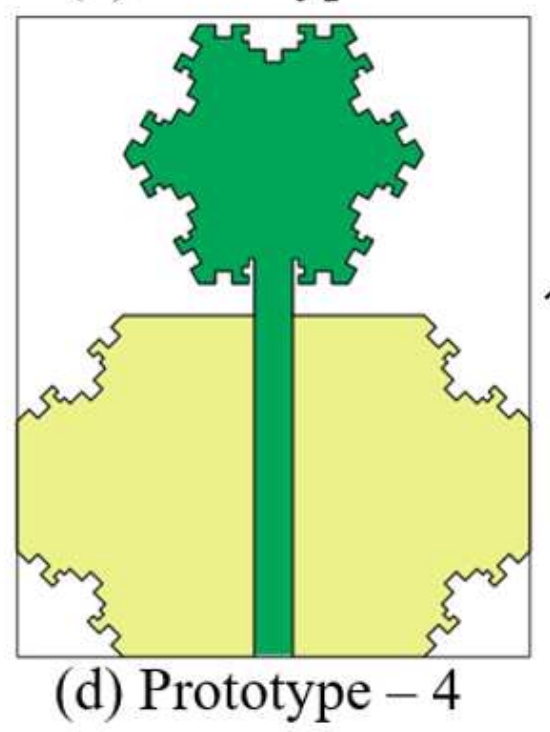

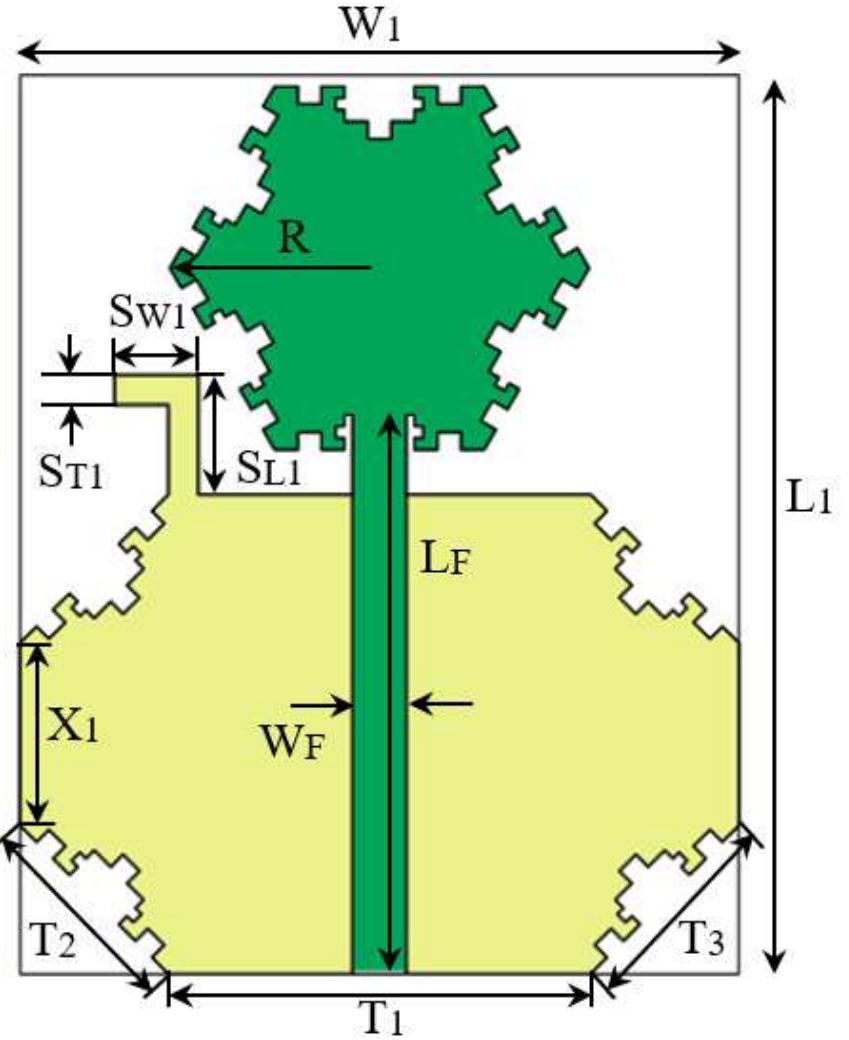

(e) Proposed Prototype

Figure 2

Design evolution of the proposed hybrid antenna (a) Iteration - 1, (b) Iteration - 2, (c) Iteration - 3, (d) Iteration - 4 and (e) Iteration - 5 (proposed prototype) 


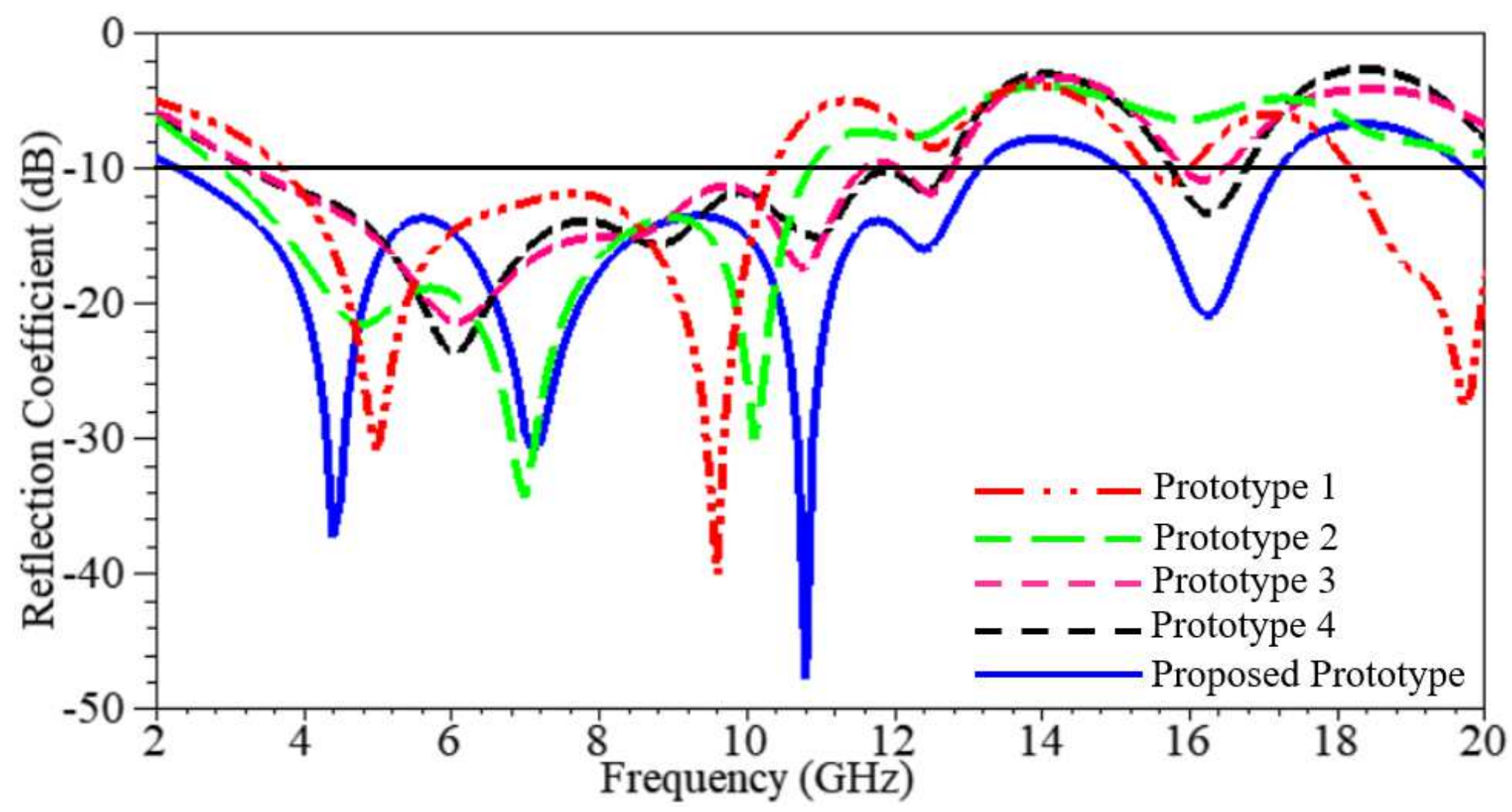

Figure 3

S11 plot for the different prototypes of the proposed hybrid antenna

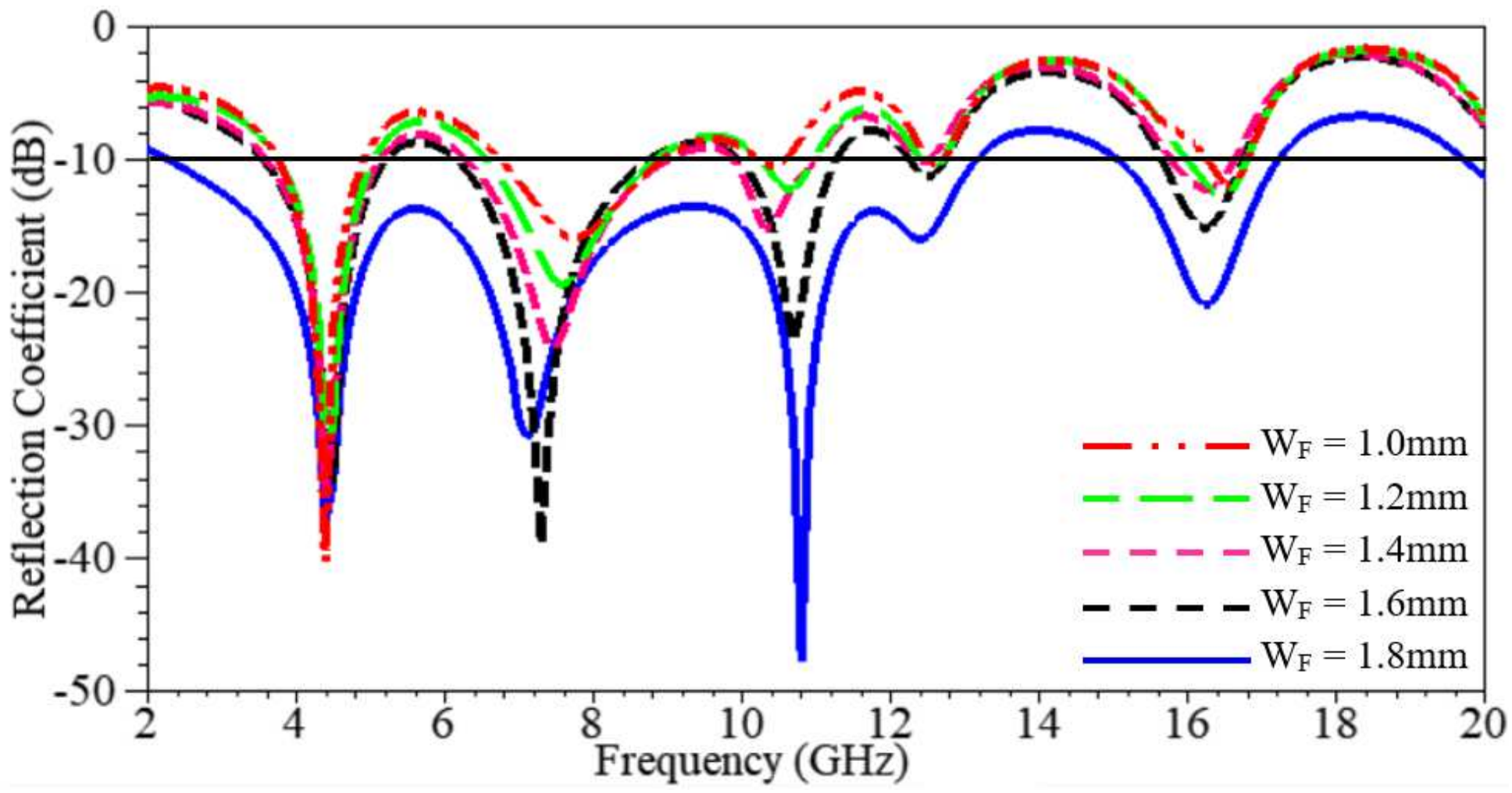

Figure 4

S11 plot of proposed hybrid antenna at different values of 'WF' parameter 


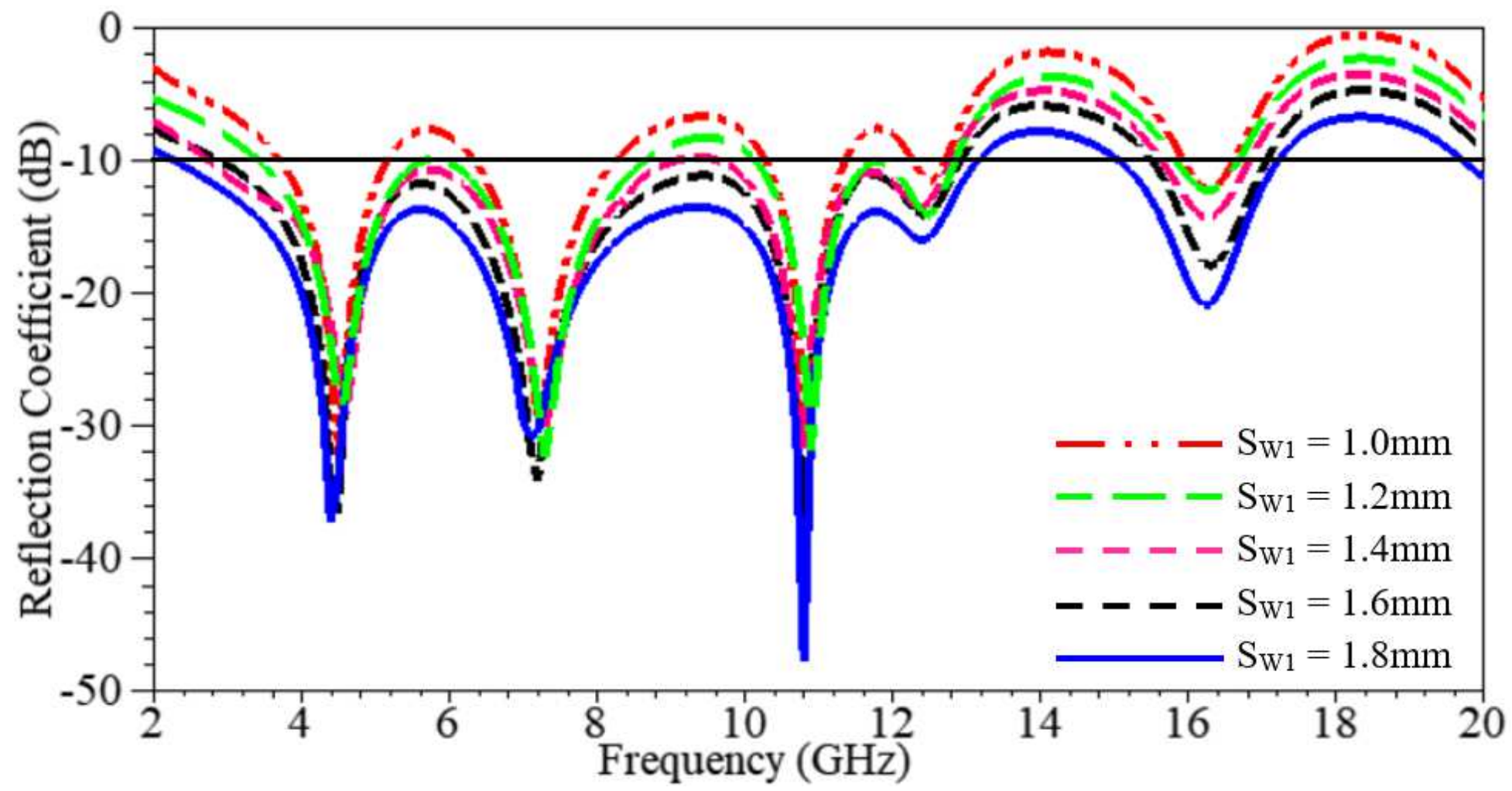

Figure 5

S11 plot of proposed hybrid antenna at different values of 'SW1' parameter 

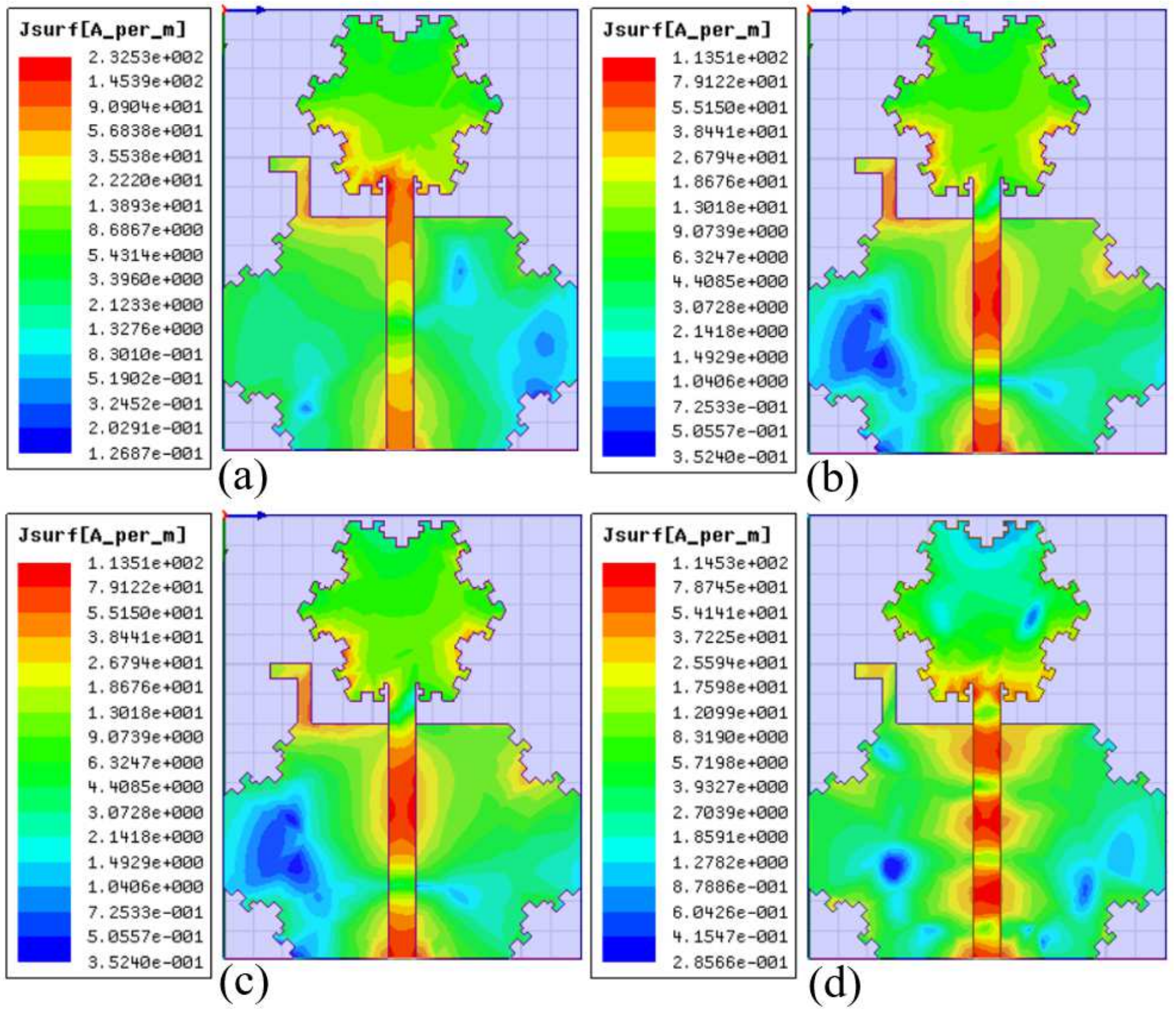

Figure 6

Simulated surface current distribution plot of proposed hybrid antenna at (a) $4.4 \mathrm{GHz}$, (b) $7.1 \mathrm{GHz}$, (c) $10.8 \mathrm{GHz}$ and (d) $16.3 \mathrm{GHz}$ frequency points 


\section{Figure 7}

Front and rear view of fabricated prototype of proposed hybrid antenna

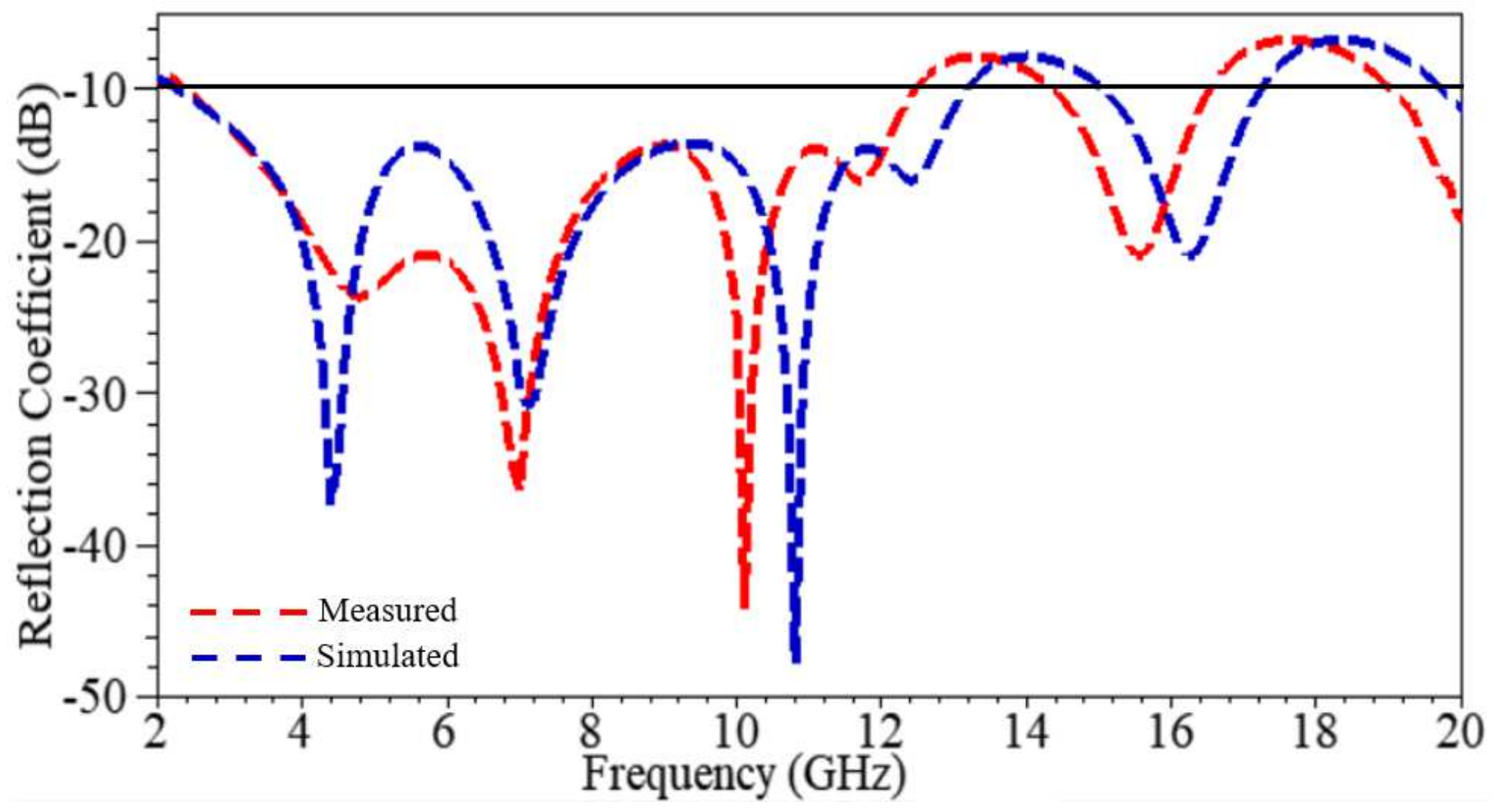

Figure 8

Simulated and measured reflection coefficient plot of proposed hybrid antenna 

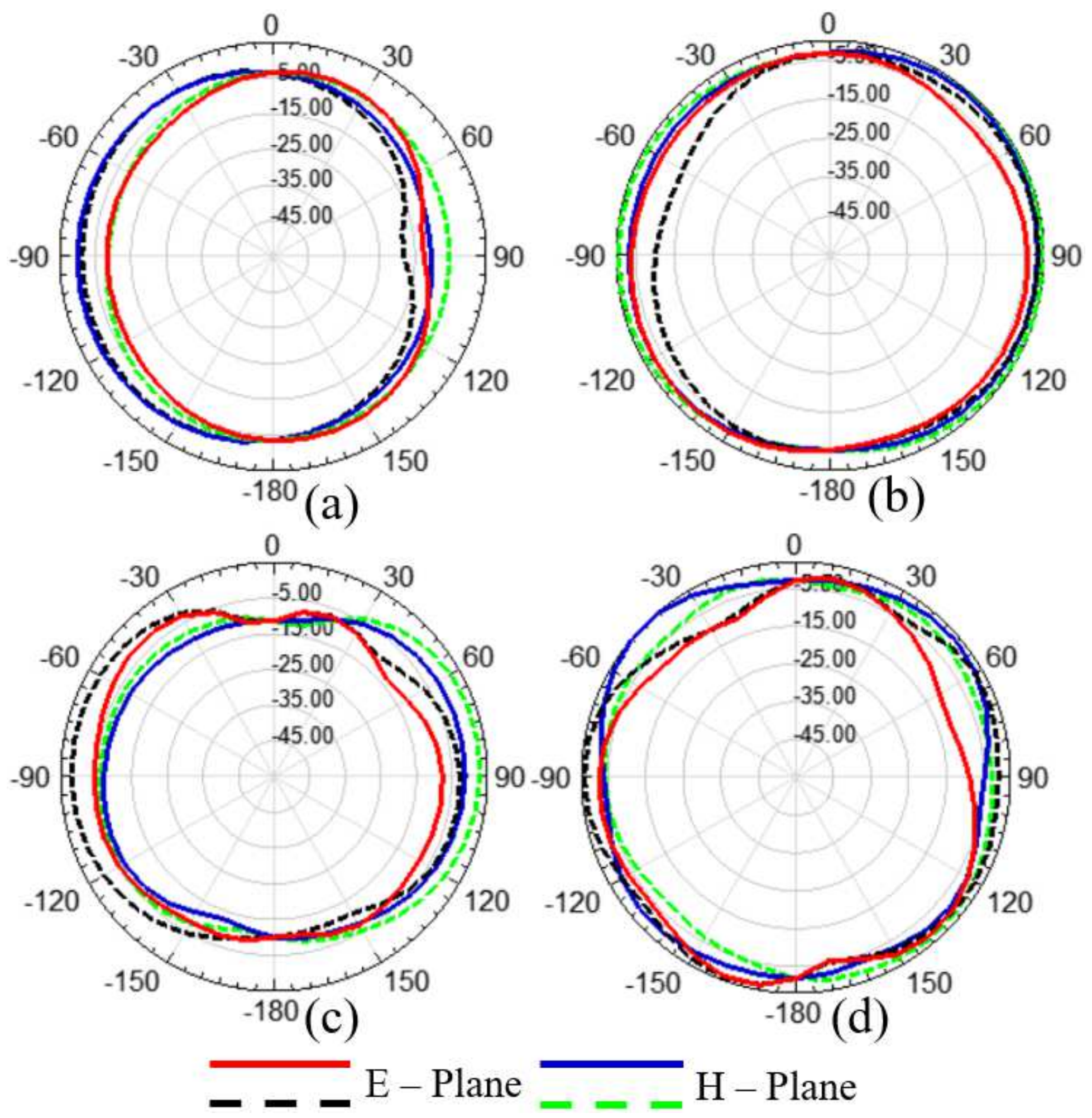

Figure 9

Radiation pattern of proposed hybrid antenna at (a) $4.4 \mathrm{GHz}$, (b) $7.1 \mathrm{GHz}$, (c) $10.8 \mathrm{GHz}$ and (d) $16.3 \mathrm{GHz}$ frequency points (solid line: simulated and dashed line: measured) 


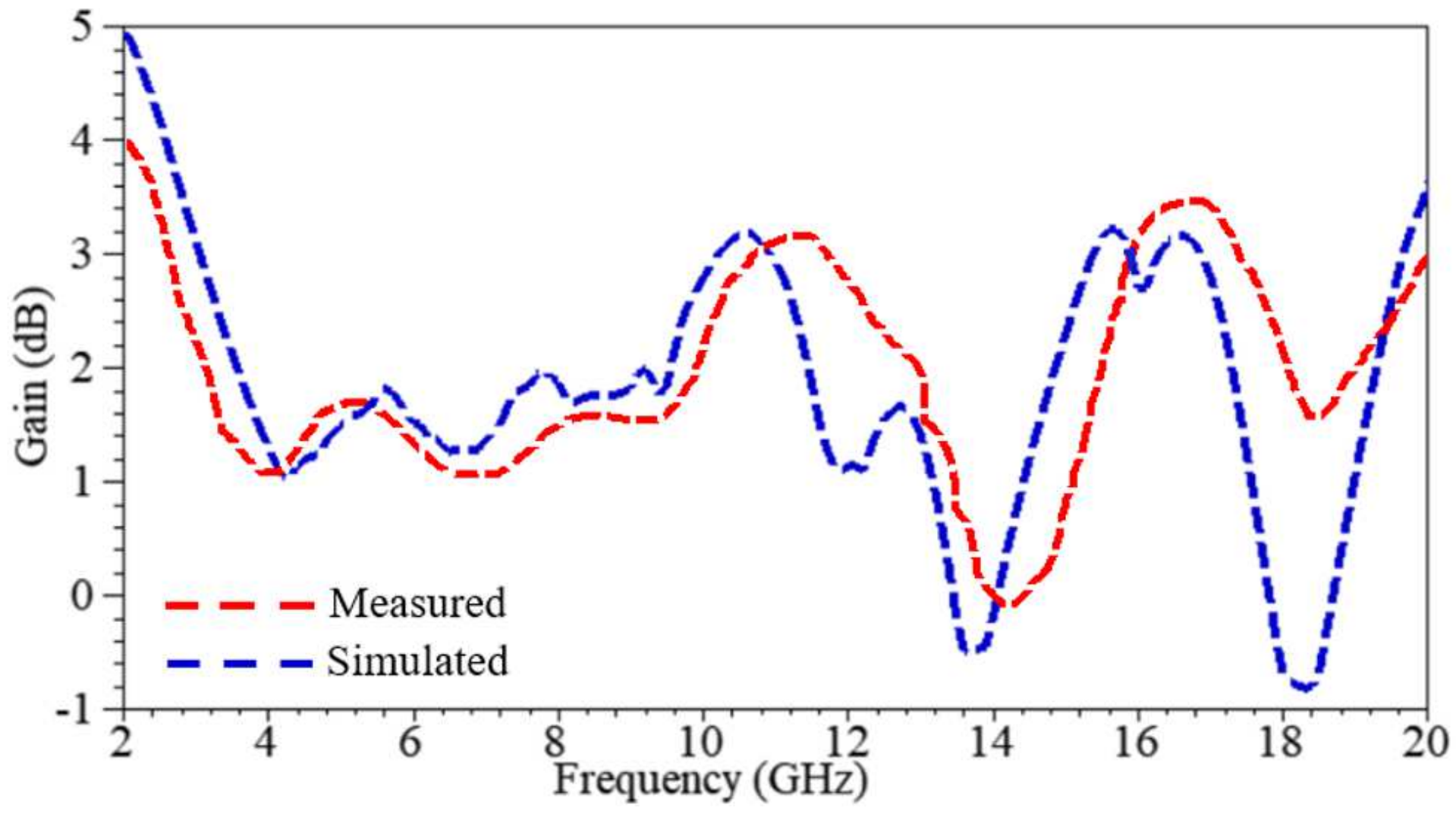

Figure 10

Simulated and measured peak realized gain of proposed hybrid antenna 